\title{
The solving of optimizing the structure of a transport node problem by the fuzzy set method
}

\author{
Liliya Kushchenko ${ }^{1 *}$ and Sergey Kushchenko ${ }^{1}$ \\ ${ }^{1}$ Belgorod State Technological University named after V.G. Shukhova, Russia
}

\begin{abstract}
One of the main tasks in the road traffic organization is to create fast, convenient and safe traffic on the road network. For this purpose, the main factors influencing the technical and economic indicators for the construction of intersections of various complexity are determined [1,2]. These include: capital costs, taking into account reconstruction and installation; the area of the territory for the intersection device; the degree of danger of the intersection; maintenance costs; accident rate of the site; road capacity; impact on the environmental situation of the environment.
\end{abstract}

Choosing the ratio of intersections with the use of technical means of traffic management in the overall structure of a transport hub is a typical optimization problem [3,4]. However, it is impossible to construct an objective function using classical methods of mathematics due to inaccurate information about the listed factors. To cope with this problem will help the field of mathematics, which is called fuzzy sets $[5,6]$.

To select the optimal ratio of regulated and unregulated intersections with the use of technical means of traffic management in the overall structure of the transport hub, it is proposed to use seven fuzzy criteria corresponding to the above factors:

$T_{1}$ - capital expenditures including reconstruction and installation technical means of traffic management, $\mathrm{K}$, o.e.

$T_{2}$ - the area of the alienated territory for the organization of the event, S, o.e.

$T_{3}$ - degree of danger of crossing, $\mathrm{m}$, o.e.

$T_{4}$ - maintenance costs, C, o.e.

$T_{5}-$ accident rate of the site, TA, o.e.

$T_{6}$ - road capacity, $\mathrm{P}$, o.e.

$T_{7}$ - impact on the environmental situation of the environment, Ec, o.e.

The quantitative assessment of each criterion is made on the basis of expert assessments and statistical data on the range of their changes.

The solution to this problem is made by one option-criteria of varying degrees of importance.

In fact, the criteria of the $T_{j}$, have different degrees of importance, since the degree of their significance in the overall structure of the criteria is different. For example, the criteria $T_{2}, T_{3}, T_{5}$ and $T_{6}$ depend not only on the location of the transport node, but also on the configuration of the intersection, the location of the centers of attraction, the availability of

*Corresponding author: lily-041288@mail.ru 
technical means of traffic management and the functional features of the transport node. When the criteria $T_{j}$, have different importance, then each of them is assigned a degree of importance $\alpha_{j} \geq 0$, (the more important the criterion, the greater a), and the selection rule takes the form:

$$
M=T_{1}^{\alpha_{1}} \cap T_{2}^{\alpha_{2}} \cap \ldots \cap T_{j}^{\alpha_{n}},
$$

where $\alpha_{j} \geq 0$;

$j=1 . . n$;

$$
\frac{1}{n} \sum_{j=1}^{n} \alpha_{j}=1
$$

$n$ - number of criteria.

The coefficients of relative importance are determined based on the procedure of paired comparison of criteria. First, a matrix of paired comparisons $K$ is formed, the elements of which are found in table 1 and satisfy the following conditions: $m_{i i}=1 ; m_{i j}=1 / m_{i j}$ :

$$
K=\left(m_{i j}\right)=\left(\begin{array}{cccc}
m_{11} & m_{12} & . . & m_{1 n} \\
m_{21} & m_{22} & . . & m_{2 n} \\
. . & . . & . . & . . \\
m_{n 1} & m_{n 2} & . . & m_{n n}
\end{array}\right) .
$$

For the purposes of expert evaluation, a 9-point scale of correspondences was adopted

\begin{tabular}{|c|c|c|}
\hline $\begin{array}{l}\text { The intensity of the } \\
\text { relative } \\
\text { importance of the } \\
\text { criteria points }\end{array}$ & $\begin{array}{l}\text { The degree of } \\
\text { significance of the } \\
\text { criteria }\end{array}$ & $\begin{array}{c}\text { Explanation of the experts ' assessment of } \\
\text { the } \\
\text { importance of the criteria }\end{array}$ \\
\hline 1 & Equal importance & The importance of the criterion (factors) $T_{i}=T_{j}$ \\
\hline 3 & $\begin{array}{l}\text { Moderate superiority of } \\
\text { one over the other }\end{array}$ & $\begin{array}{l}\text { Experience and judgment give an easy } \\
\text { superiority to one criterion over another }\end{array}$ \\
\hline 5 & Substantial superiority & $\begin{array}{c}\text { The available data shows a marked superiority } \\
\text { of } T_{i} \text { over } T_{j}\end{array}$ \\
\hline 7 & Very strong superiority & $\begin{array}{c}\text { The superiority of the criterion } T_{i} \text { over } T_{j} \text { is } \\
\text { obvious }\end{array}$ \\
\hline 9 & Absolute superiority & $\begin{array}{c}\text { Очевидность превосходства over } T_{j} \\
\text { подтверждается всеми имеющимися } \\
\text { признаками } \\
\text { The evidence of the superiority of the } T_{i} \text { over } \\
\text { the } T_{j} \text { is confirmed by all the available signs }\end{array}$ \\
\hline $2,4,6,8$ & $\begin{array}{l}\text { Intermediate decisions } \\
\text { between two adjacent } \\
\text { judgments }\end{array}$ & They are used in compromise cases \\
\hline
\end{tabular}
based on the Saati hierarchy analysis method [9].

Table 1 The scale of relative importance of criteria

Next, the eigenvector of the $K-w$ matrix corresponding to the maximum eigenvalue of $z_{\max }$ is determined.

The desired coefficients $\alpha_{j}$ are obtained by multiplying the elements $w_{i}$ (priority vector $T_{j}$ ) by $n$ (the number of criteria under consideration $n=6$ ) to fulfill the condition [10]:

$$
\alpha_{j}=n \cdot w_{i}
$$

As a result of statistical and expert evaluation, the topics for linguistic variables and the range of their possible values were selected $[7,8]$. To describe the criteria $T_{1}-T_{7}$, four 
functional input linguistic variables (terms) are introduced. The ranges of linguistic variables are given in relative units for each $T_{j}$ criterion and are presented in Table 2.

Table 2. The range of changes in the linguistic variables of each criterion

\begin{tabular}{|c|c|c|c|c|c|}
\hline \multirow{2}{*}{ № } & \multirow{2}{*}{ Linguistic variables } & \multicolumn{4}{|c|}{ Thermae } \\
\cline { 3 - 6 } & & ZP & PS & PM & PB \\
\hline & $T_{1}, K$ & {$[0 ; 0,1 ; 0,3]$} & {$[0,25 ; 0,4 ; 0,55]$} & {$[0,47 ; 0,6 ; 0,73]$} & {$[0,7 ; 0,9 ; 1]$} \\
\hline & $T_{2}, S$ & {$[0 ; 0,05 ; 0,2]$} & {$[0,15 ; 0,3 ; 0,45]$} & {$[0,4 ; 0,55 ; 0,7]$} & {$[0,65 ; 0,9 ; 1]$} \\
& $T_{3}, m$ & - & {$[0 ; 0,15 ; 0,4]$} & {$[0,3 ; 0,5 ; 0,7]$} & {$[0,6 ; 0,85 ; 1]$} \\
\hline & $T_{4}, C$ & - & {$[0 ; 0,2 ; 0,4]$} & {$[0,2 ; 0,5 ; 0,8]$} & {$[0,6 ; 0,8 ; 1]$} \\
\hline & $T_{5}, T A$ & {$[0 ; 0,05 ; 0,3]$} & {$[0,25 ; 0,4 ; 0,55]$} & {$[0,45 ; 0,6 ; 0,75]$} & {$[0,7 ; 0,95 ; 1]$} \\
\hline & $T_{6}, P$ & - & {$[0 ; 0,15 ; 0,35]$} & {$[0,2 ; 0,5 ; 0,8]$} & {$[0,65 ; 0,85 ; 1]$} \\
\hline & $T_{7}, E c$ & - & {$[0 ; 0,1 ; 0,35]$} & {$[0,3 ; 0,5 ; 0,7]$} & {$[0,65 ; 0,9 ; 1]$} \\
\hline
\end{tabular}

$\mathrm{ZP}$ - «positive close to zero; PS- «positive small»; PM - «positive average»; PB - « positive large»

The construction of the accessory functions for each criterion begins with an estimated calculation of the possible range of changes in quantitative estimates at comparable prices, and the results are tabulated. Then statistical processing is performed and the number of hits of the calculated values in one of the intervals $\left(\left(v_{i j}\right), i=1 \div 6, j=1 \div 9\right)$ is determined. The values of the membership functions are calculated using the formula [11]:

$$
\mu_{i j}=\frac{v_{i j}}{v_{i \max }},
$$

where $v_{\text {imax }}$ - maximum value of the element in the $i$-th row.

We will select the optimal structure of the transport hub with the use of technical means of organizing traffic in this way, taking into account the different importance of the criteria.

In accordance with the scale of relative importance, a matrix $K$ of the above requirements for the transport node is formed:

$$
K=\left(m_{i j}\right)=\left(\begin{array}{ccccccc}
1 & 7 & 5 & 1 & 5 & 1 & 1 \\
0,143 & 1 & 3 & 0,2 & 0,2 & 0,333 & 7 \\
0,2 & 0,333 & 1 & 0,2 & 0,333 & 1 & 0,2 \\
1 & 5 & 5 & 1 & 1 & 1 & 0,333 \\
0,2 & 5 & 3 & 1 & 1 & 3 & 0,333 \\
1 & 3 & 1 & 1 & 0,333 & 1 & 0,333 \\
1 & 0,143 & 5 & 3 & 3 & 3 & 1
\end{array}\right)
$$

- moderate superiority of criteria is accepted $T_{1}$ and $T_{7}$ above the criteria $T_{4}$ and $T_{6}$;

- significant superiority of the criteria $T_{1}$ and $T_{7}$ above the criterion $T_{3}$ and $T_{4}, T_{5}$ над $T_{2}$

- very strong criteria superiority $T_{1}$ and $T_{7}$ above the criterion $T_{2}$;

- moderate superiority of criteria $T_{4}$ and $T_{5}$ above the criterion $T_{6}$;

- moderate superiority of the criterion $T_{3}$ above the criterion $T_{2}$;

- equal importance of criteria $T_{1}$ and $T_{7}, T_{4}$ and $T_{6}$;

- moderate superiority $T_{3}, T_{6}$ above the criterion $T_{2}$;

- moderate superiority to criteria $T_{5}$ above the criterion $T_{3}$;

- equal importance of criteria $T_{6}$ and $T_{3}, T_{4}$ and $T_{5}$;

- moderate superiority of the criterion $T_{7}$ above the criterion $T_{5}$;

- significant superiority of the criterion $T_{4}$ above the criterion $T_{3}$. 
Based on the obtained matrix $K$, the eigenvector of pairwise comparisons of this matrix is determined:

$$
w=\left(\begin{array}{c}
0,601 \\
0,362 \\
0,08 \\
0,371 \\
0,358 \\
0,25 \\
0,416
\end{array}\right) ;
$$

Hence the relative importance coefficients are:

$$
\begin{aligned}
& \alpha_{1}=n \cdot w_{1}=7 \cdot 0,601=4,207 \\
& \alpha_{2}=n \cdot w_{2}=7 \cdot 0,362=2,534 ; \\
& \alpha_{3}=n \cdot w_{3}=7 \cdot 0,08=0,56 \\
& \alpha_{4}=n \cdot w_{4}=7 \cdot 0,371=2,597 \\
& \alpha_{5}=n \cdot w_{5}=7 \cdot 0,358=2,506 \\
& \alpha_{6}=n \cdot w_{6}=7 \cdot 0,25=1,75 \\
& \alpha_{7}=n \cdot w_{7}=7 \cdot 0,416=2,912
\end{aligned}
$$

Hence, membership functions with a modified set of requirements are obtained:

$$
\begin{aligned}
& \mathrm{T}_{1}^{\alpha 1}=\mathrm{T}_{1}^{4,207}=\left\{\begin{array}{l}
0,054 / A_{1} ; 0,197 / A_{2} ; 0,117 / A_{3} ; 0,0011 / A_{4} ; \\
0,117 / A_{5} ; 0,012 / A_{6} ; 0,298 / A_{7} ; 0,0642 / A_{8} ;
\end{array}\right\} \\
& \mathrm{T}_{2}^{\alpha 2}=\mathrm{T}_{2}^{2,534}=\left\{\begin{array}{c}
1 / A_{1} ; 0,336 / A_{2} ; 0,098 / A_{3} ; 0,0046 / A_{4} ; \\
0,0057 / A_{5} ; 0,173 / A_{6} ; 0,274 / A_{7} ; 0,568 / A_{8} ;
\end{array}\right\} ; \\
& \mathrm{T}_{3}^{\alpha 3}=\mathrm{T}_{3}^{0,56}=\left\{\begin{array}{l}
1 / A_{1} ; 0,883 / A_{2} ; 0,751 / A_{3} ; 0,333 / A_{4} ; \\
0,858 / A_{5} ; 0,333 / A_{6} ; 0,883 / A_{7} ; 1 / A_{8} ;
\end{array}\right\} \\
& \mathrm{T}_{4}^{\alpha 4}=\mathrm{T}_{4}^{2,597}=\left\{\begin{array}{c}
1 / A_{1} ; 0,01 / A_{2} ; 0,025 / A_{3} ; 0,616 / A_{4} ; \\
0,579 / A_{5} ; 0,033 / A_{6} ; 1 / A_{7} ; 1 / A_{8} ;
\end{array}\right\} ; \\
& \mathrm{T}_{5}^{\alpha 5}=\mathrm{T}_{5}^{2,506}=\left\{\begin{array}{c}
0,96 / A_{1} ; 0,572 / A_{2} ; 0,302 / A_{3} ; 0,101 / A_{4} ; \\
0,034 / A_{5} ; 0,101 / A_{6} ; 0,025 / A_{7} ; 0,572 / A_{8} ;
\end{array}\right\} ; \\
& \mathrm{T}_{6}^{\alpha 6}=\mathrm{T}_{6}^{1,75}=\left\{\begin{array}{l}
0,05 / A_{1} ; 0,496 / A_{2} ; 0,677 / A_{3} ; 0,483 / A_{4} ; \\
0,076 / A_{5} ; 0,05 / A_{6} ; 0,604 / A_{7} ; 0,722 / A_{8} ;
\end{array}\right\} ; \\
& \mathrm{T}_{7}^{\alpha 7}=\mathrm{T}_{7}^{2,912}=\left\{\begin{array}{c}
1 / A_{1} ; 0,055 / A_{2} ; 0,133 / A_{3} ; 0,4 / A_{4} ; \\
0,433 / A_{5} ; 0,009 / A_{6} ; 0,025 / A_{7} ; 0,069 / A_{8} ;
\end{array}\right\}
\end{aligned}
$$

A visual representation of the modified set of requirements with different importance of criteria, from which the degree of influence of each criterion on the choice of the optimal structure of the transport node with the use of technical means of traffic management is clearly visible, is shown in Figure 1. 


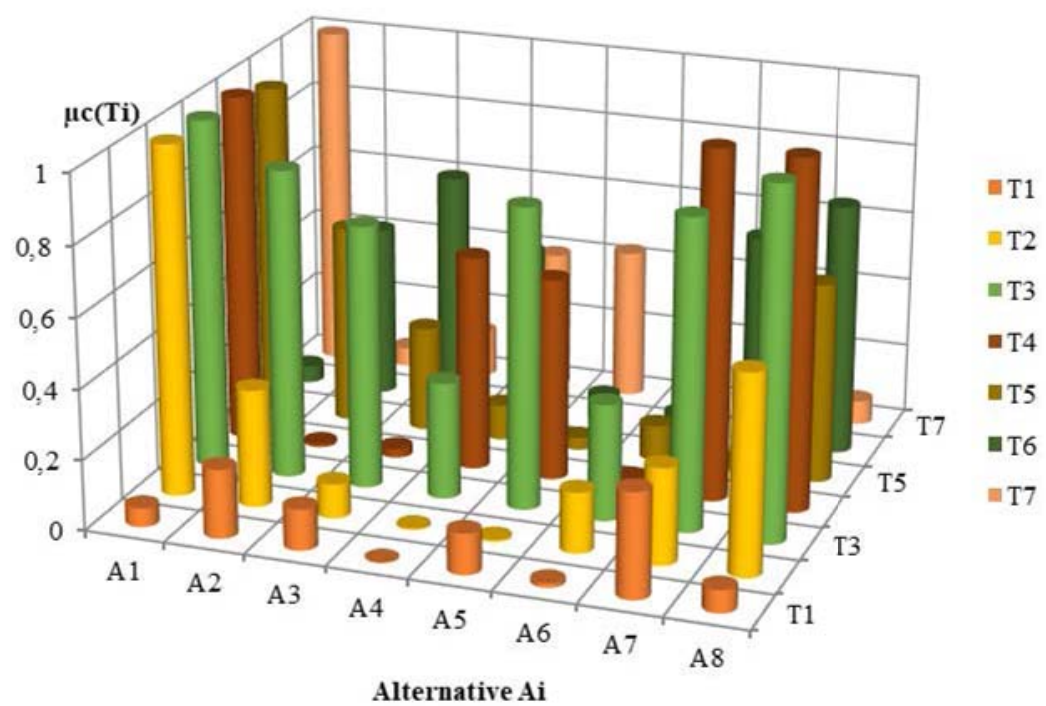

Fig. 1. Evaluation of the functions of belonging to the types of transport node under different criteria with different degrees of importance

Using the proposed rule, we first determine the minimum values of the membership function, from which we choose the maximum. Based on the decision according to the algorithm proposed above, the best option, taking into account the different importance of the criteria, is the eighth choice.

$$
F_{8}^{*}=\{0,0642 ; 0,568 ; 1 ; 1 ; 0,572 ; 0,722 ; 0,069\} .
$$

Given that this solution allows to more accurately take into account the impact of the criteria, we accept the structure of the transport node (two-level interchange + traffic light object).

\section{References}

1. L. E. Guy, A. I. Shutov, P. A. Volya, S. V. Kushchenko. Congestion phenomena. Warning features // Bulletin of BSTU named after V. G. Shukhov. No. 3. pp. 166-169. (2013)

2. Kushchenko L. E. Organization of road traffic / L. E. Kushchenko, S. V. Kushchenko, A. N. Novikov, I. A. Novikov-Belgorod: Publishing house of BSTU named after V. G. Shukhov, - 196 p. (2020)

3. Rodionov M. A., Zudina T. A. Introduction to "FUZZY LOGIC" / Textbook. Penza, V. G. Belinsky State Pedagogical University, (2006)

4. Kofman A. Introduction to the theory of fuzzy sets M.: Radio and Communication, (1982)

5. Saati, T. Decision-making. Method of analyzing hierarchies / T. Saati. - M.: Radio and Communication, 1993. - $278 \mathrm{p}$.

6. Anshin V. M., Demkin I. V., Tsarkov I. N., Nikonov I. M. Application of the theory of fuzzy sets to the problem of project portfolio formation / / Problems of risk analysis. - Vol. 5. - no. 3. - p. 8-21. (2008) 
7. L. E. Kushchenko Fuzzy logic-based traffic flow modeling / S. V. Kushchenko, I. A. Novikov, A. N. Novikov, V. I. / / International Journal of Pharmacy and Technology,. pp. 24856-24867. (2016)

8. Arkhipova, N. I. Theory of system analysis and management: textbook. handbook for universities / N. I. Arkhipova, V. V. Kulba, S. A. Kosyachenko-M.: "PRIOR Publishing House", - 384 p. (2008)

9. Saati, T. Decision-making. Analytic hierarchy process / T. Saaty. - M.: Radio and communication, 278 c. (1993)

10. Moradifar A., Foroud, A. A. and K. G. Firouzjah Comprehensive identification of multiple harmonic sources using fuzzy logic and adjusted probabilistic neural network //Neural Computingand Applications. Vol. 31. no. 1. pp. 543-556. (2019)

11. Yudin D. A., Migergot V. Z. Automated system of fuzzy estimates of the parameters of the roasting process on the basis of image analysis // Industrial automatic control systems and controllers. no. 10. pp. 3-13. (2014) 